\title{
Online dynamical downscaling of temperature and precipitation within the $i$ LOVECLIM model (version 1.1)
}

\author{
Aurélien Quiquet $^{1}$, Didier M. Roche ${ }^{1,2}$, Christophe Dumas ${ }^{1}$, and Didier Paillard ${ }^{1}$ \\ ${ }^{1}$ Laboratoire des Sciences du Climat et de l'Environnement, LSCE/IPSL, CEA-CNRS-UVSQ, Université Paris-Saclay, \\ 91191 Gif-sur-Yvette, France \\ ${ }^{2}$ Earth and Climate Cluster, Faculty of Earth and Life Sciences, Vrije Universiteit Amsterdam, Amsterdam, the Netherlands
}

Correspondence: Aurélien Quiquet (aurelien.quiquet@1sce.ipsl.fr)

Received: 9 May 2017 - Discussion started: 1 June 2017

Revised: 27 November 2017 - Accepted: 28 November 2017 - Published: 1 February 2018

\begin{abstract}
This paper presents the inclusion of an online dynamical downscaling of temperature and precipitation within the model of intermediate complexity $i$ LOVECLIM v1.1. We describe the following methodology to generate temperature and precipitation fields on a $40 \mathrm{~km} \times 40 \mathrm{~km}$ Cartesian grid of the Northern Hemisphere from the T21 native atmospheric model grid. Our scheme is not grid specific and conserves energy and moisture in the same way as the original climate model. We show that we are able to generate a highresolution field which presents a spatial variability in better agreement with the observations compared to the standard model. Although the large-scale model biases are not corrected, for selected model parameters, the downscaling can induce a better overall performance compared to the standard version on both the high-resolution grid and on the native grid. Foreseen applications of this new model feature include the improvement of ice sheet model coupling and highresolution land surface models.
\end{abstract}

\section{Introduction}

In recent decades, the Earth has undergone a sustained global warming due to a rapid rise in greenhouse gases, a rise unprecedented over the last million years (Luthi et al., 2008; Wolff, 2011). Some components of the Earth system, such as the oceanic and terrestrial carbon cycles or the continental ice sheets, present feedbacks acting over long timescales, i.e. multi-millennial, and are suspected to play an important role for the climate in the future (Archer and Brovkin, 2008). Earth models of intermediate complexity (EMICs) are pow- erful tools to investigate the long-term transient response of the climate system (Claussen et al., 2002). The advantage of EMICs is to include most of the major climatic components in a unified and coupled framework whilst being computationally inexpensive compared to more comprehensive general circulation models (known as GCMs) because of a simplified physics and a coarser resolution. As such, they can be used to perform numerous simulations to assess model sensitivities (e.g. Loutre et al., 2011) or multi-millennial integrations to study slower feedback responses (e.g. Calov et al., 2005). EMICs were initially developed as computationally cheap alternatives to general circulation models especially in the context of studying the role of orbital and carbon dioxide forcing and feedback within the context of glacialinterglacial cycles (Weaver et al., 1998; Berger et al., 1998; Ganopolski et al., 1998). With the addition of interactive ice sheets, EMICs became capable of studying ice sheet dynamics in terms of retreat, advance and stability as a key component of the climate system (Calov et al., 2002; Huybrechts et al., 2002; Charbit et al., 2005). Also, some EMICs include an interactive carbon cycle which allows the investigation of the mechanisms behind the atmospheric carbon dioxide fluctuations during the Quaternary (e.g. Brovkin et al., 2007; Ridgwell and Hargreaves, 2007; Bouttes et al., 2011). However, with increases in computing facilities, EMICs are generally becoming more comprehensive than they have ever been. From zonally averaged atmosphere or ocean (e.g. Gallée et al., 1992; Petoukhov et al., 2000), they now often include a three-dimensional ocean (e.g. Edwards and Marsh, 2005; Weaver et al., 2001). Yet, the atmospheric component has remained a simplified component in EMICs even though 
it may sometimes be three-dimensional, but with only a limited number of vertical levels and slightly simplified base equations (Goosse et al., 2010).

However, the relative simplicity and coarse resolution of such climate models result in an approximative representation of land surface climatic variables that show a high spatial variability. Precipitation is an example of such a variable, being a key component of the climate system and nonetheless generally poorly represented in atmospheric models. In particular, EMICs are unable by design to correctly reproduce the meso-scale atmospheric processes induced by relatively fine-scale topographic features such as mountain ranges. This has important consequences for the sub-components of the climate system that depend on the atmospheric water cycle such as surface hydrology, vegetation or water isotopes. Higher resolution is thus imperative for components whose large-scale physical behaviour is highly dependent upon processes occurring on small spatial scales. The limitations induced by coarse resolution has led to it becoming a recurrent issue in climate-hydrology studies on the basin scale (e.g. Vetter et al., 2015) and in ice-sheet-climate coupling studies (e.g. Charbit et al., 2005; Fyke et al., 2011).

In particular, ice sheet models require a higher resolution to account for the narrow ablation zones at the ice sheet margins (Ettema et al., 2009). To account for it, ice-sheetclimate coupled models have often preferred to use their own anomalies regridded on top of a reference climate to force the ice sheet model (e.g. Vizcaíno et al., 2008; Goelzer et al., 2016). The anomalies are then linearly interpolated and added to well-constrained and high-resolution presentday climate fields. Such a strategy implicitly assumes that the model biases remain unchanged through time and are independent from the imposed external forcings, and also remain unchanged as ice sheet geometry changes significantly. Alternatively, another strategy is to use absolute fields, but downscaled to the needed resolution. The complexity of such downscaling approaches ranges from simple bi-linear interpolations (e.g. Vizcaíno et al., 2010; Gregory et al., 2012) to more physically based approaches. To achieve temperature downscaling, Charbit et al. (2005) duplicate the energy budget calculation on 15 artificial levels in order to retrieve surface temperature on a vertically extended grid; whereas Fyke et al. (2011) follow a similar strategy but derived precipitation on the vertical extended grid in addition. Alternatively, Robinson et al. (2010) embed a simplified regional energymoisture balance model in an EMIC in order to assess subgrid processes unresolved by their native atmospheric model. Although statistical downscaling has been applied to EMIC outputs (Vrac et al., 2007; Levavasseur et al., 2011), these techniques were not used to couple the various different components of models.

Here we present the inclusion of a relatively inexpensive online and conservative dynamical downscaling of temperature and precipitation in the $i$ LOVECLIM coupled climate model (version 1.1). The downscaling is done from the na- tive T21 grid $\left(\simeq 5.625^{\circ}\right.$ spatial resolution) towards a cartesian $40 \mathrm{~km} \times 40 \mathrm{~km}$ grid of the Northern Hemisphere. The chosen high-resolution grid arises from the ice sheet model grid embedded in iLOVECLIM (Roche et al., 2014). The methodology chosen for the downscaling procedure is to first replicate the original model physics on artificial surfaces of a vertically extended grid. Then from the vertically extended grid, we compute the precipitation, explicitly taking into account the sub-grid orography following the original model physics. Computed on each atmospheric time step, the downscaling accounts for the feedback of sub-grid precipitation on the large-scale energy and water budgets. Although the energy repartition between the turbulent fluxes is modified, the conservation, however, is ensured in the same way as in ECBilt, where the heat flux towards land and ocean is computed as the imbalance between the incoming (both shortwave and longwave) and the outgoing radiation (longwave only) as well as the turbulent (latent and sensible) heat fluxes. The conservation of energy and water is particularly important for multi-millennial simulations. As the downscaling methodology is not grid specific, it can be applied in the future to any grid having a higher resolution than the native T21 grid. In particular, downscaling over a specific region (e.g. Europe or the Andes) is possible with our implementation. Foreseen future applications include ice-sheet surface mass balance computation and land surface modelling (hydrology, permafrost, vegetation dynamics and land carbon) on the continental scale and at high resolution.

In Sect. 2 we describe the implementation of the dynamical downscaling of temperature and precipitation in the atmospheric component of the $i$ LOVECLIM model. In Sect. 3 we discuss the performance of both the standard and downscaled temperature and precipitation fields in representing presentday climatological fields. Finally we list concluding remarks and perspectives in Sect. 4.

\section{Methodology}

\subsection{The $i$ LOVECLIM model}

$i$ LOVECLIM (here in version 1.1) is a fork of the LOVECLIM 1.2 model code, extensively described in Goosse et al. (2010). Whilst the physics in the atmosphere, ocean and land surface has remained mostly unchanged, the major bifurcations from Goosse et al. (2010) consist of the addition of a water oxygen isotope cycle (Roche, 2013; Roche and Caley, 2013), an oceanic carbon model (Bouttes et al., 2015), an alternative ice sheet model (Roche et al., 2014), the reimplementation of the initial iceberg model (Bügelmayer et al., 2015) and a permafrost model (Kitover et al., 2015). The LOVECLIM family of models contain a free surface ocean general circulation model with an approximately $3^{\circ}$ spatial resolution and 20 vertical layers. It is coupled to a thermodynamical sea ice model operating on the same spatial grid. 


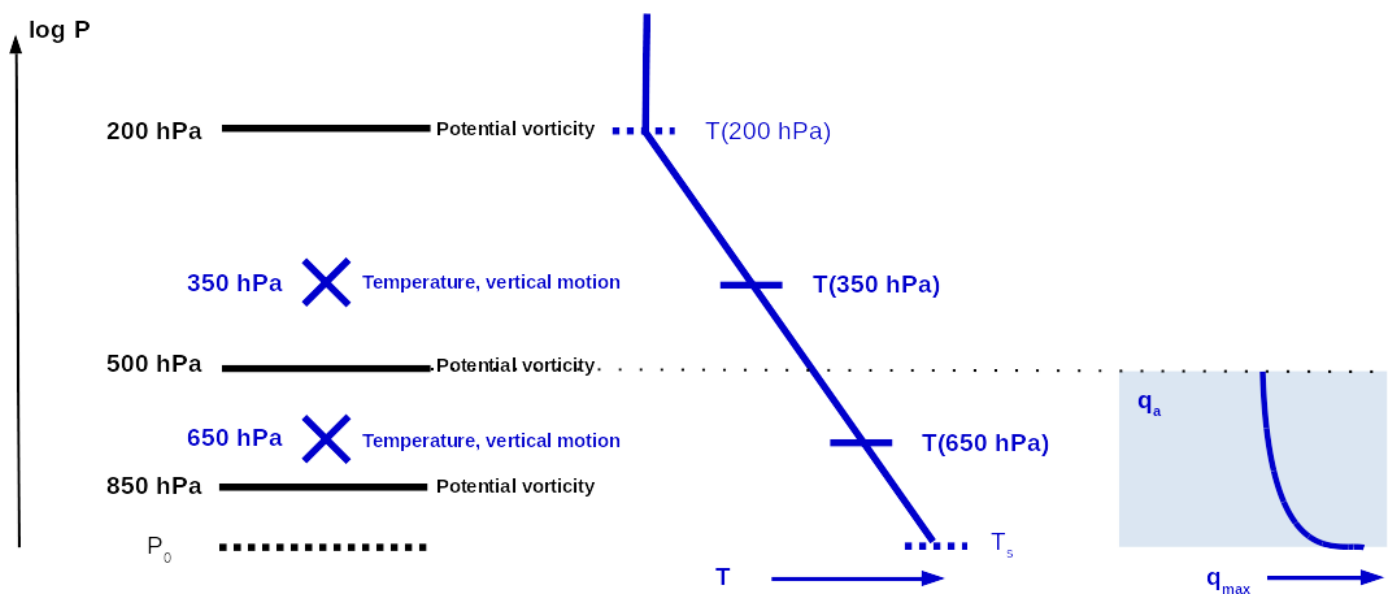

Figure 1. Schematic representation of the atmosphere in ECBilt. The three levels for the vorticity equation are 200,500 and $850 \mathrm{hPa}$. The temperature is effectively computed for 350 and $650 \mathrm{hPa}$, and then linearly interpolated on a log scale to any other pressure level. The saturation profile in the moist layer (below $500 \mathrm{hPa}$ ) is computed from tabulated values.

The atmospheric component of main concern here, ECBilt, is a quasi-geostrophic model, solved on a T21 spectral grid. For a complete description of ECBilt, the reader is referred to Haarsma et al. (1997) and Opsteegh et al. (1998) and references therein. The dynamics, i.e. the resolution of the potential vorticity equation, are computed for three vertical levels: 850,500 and $200 \mathrm{hPa}$. The equations for temperature and vertical motion are computed on two intermediate levels at 650 and $350 \mathrm{hPa}$. A schematic representation of the vertical structure of the atmosphere in ECBilt is shown in Fig. 1.

The main idea of the downscaling procedure is to replicate the processes governing precipitation formation and surface temperature computation on a refined vertically extended grid in order to assess these variables at any altitude for any given sub-grid.

\subsection{Vertical profiles of temperature and moisture}

The first step of the downscaling is to recompute temperature and moisture variables on artificial surfaces of a vertically extended grid of the atmosphere. This grid consists in 11 vertical levels at 10, 250, 500, 750, 1000, 1250, 1500, 2000, 3000, 4000 and $5000 \mathrm{~m}$. In the following, we present the equations already described in Haarsma et al. (1997), which are needed for the vertically extended grid.

\subsubsection{Temperature profile}

In ECBilt, due to the lack of a proper representation of the atmospheric boundary layer, an idealized vertical profile is used to compute heat, moisture and momentum fluxes at the Earth surface. Above $200 \mathrm{hPa}$, the atmosphere is assumed to be isothermal. Assuming hydrostatic equilibrium and using the ideal gas law, the temperature varies linearly with the logarithm of pressure. For this reason, from the 650 and $350 \mathrm{hPa}$ intermediate levels, we compute this linear temperature pro- file with the logarithm of pressure from $200 \mathrm{hPa}$ to the surface. Thus, for any pressure level $p$, the temperature is

$T(p)=T_{650}+\gamma \ln \left(\frac{p}{p_{650}}\right)$,

with $\gamma$ being the atmospheric temperature lapse rate given as

$\gamma=\frac{T_{350}-T_{650}}{\ln \left(p_{350} / p_{650}\right)}$.

In Haarsma et al. (1997), the near-surface air temperature of an atmospheric grid cell, $\overline{T_{*}}$, is computed from $T_{500}$, using Eq. (1) to eliminate the pressure variable in the hydrostatic equilibrium equation:

$\overline{T_{*}}=\sqrt{T_{500}^{2}-\frac{2 \gamma g}{R}\left(\overline{z_{\mathrm{h}}}-z_{500}\right)}$,

where $\overline{z_{\mathrm{h}}}$ is the grid-cell surface height and $z_{500}$ the height of the $500 \mathrm{hPa}$ level (prescribed homogeneously at $5500 \mathrm{~m}$ ).

This equation is used to assess the near-surface air temperature for the 11 artificial surfaces by explicitly using their altitude, $z_{\mathrm{h}}(l=1,11)$, instead of the actual surface height of the grid cell:

$T_{*}(l=1,11)=\sqrt{T_{500}^{2}-\frac{2 \gamma g}{R}\left(f_{\mathrm{s}} z_{\mathrm{h}}(l)-z_{500}\right)}$.

The vertical lapse rate in temperature computed in the model in Eq. (2) is representative of the free-atmosphere temperature variations. Since the along-slope lapse rate is generally smaller than the free-atmosphere lapse rate (e.g. Marshall et al., 2007; Gardner et al., 2009; Minder et al., 2010), its use leads to an overestimation of the temperature changes with elevation. In order to artificially reduce the value of the vertical lapse rate in the model, we apply a global tunable 
correcting factor ( $f_{\mathrm{s}}$ in Eq. 4 ; typically ranging from 0.5 to $1)$ to the orography on the vertically extended grid.

From this near-surface air temperature for the artificial surfaces, we derive several surface energy balance terms (downward longwave radiation, latent and sensible heat fluxs) in the same way as Haarsma et al. (1997). Surface temperatures at the artificial surfaces $T_{\mathrm{S}}(l=1,11)$ are computed iteratively from the energy balance, assuming a zero heat capacity of the surface. We assume no change in surface types, and consequently albedo, between the different artificial layers. Because the latent heat flux depends on the evaporation, we also need to assess the specific humidity at the 11 artificial surface levels.

\subsubsection{Moisture profile}

In the idealized ECBilt representation of the atmosphere, only the lower part of the atmosphere (i.e. below $500 \mathrm{hPa}$ ) contains water. A single equation is used to compute the evolution of total precipitable water $\overline{q_{\mathrm{a}}}$ from advection, precipitation and evaporation. In our version of the model, precipitation occurs when the total amount of precipitable water is greater than a fraction $\left(\alpha_{q}=90 \%\right)$ of the vertically integrated saturated specific humidity $q_{\max }$. For each artificial level, the expression of $q_{\max }(l=1,11)$ is computed as in Haarsma et al. (1997) as the vertical integral of the saturated specific humidity in the pressure coordinate:

$q_{\max }(l=1,11)=\frac{1}{\rho_{\mathrm{w}} g} \int_{p_{0}(l)}^{500 \mathrm{hPa}} q_{\mathrm{s}}(T, p) \mathrm{d} p$,

where $\rho_{\mathrm{w}}$ is the water density and $g$ is the gravitational acceleration. The surface pressure $p_{0}(l=1,11)$ is computed by rearranging Eq. (1) in terms of pressure and using Eq. (2) as follows:

$p_{0}(l=1,11)=p_{650} \exp \left(\frac{T_{*}(l)-T_{650}}{\gamma}\right)$.

The saturated specific humidity at a given level, $q_{\mathrm{s}}(T, p)$, is given by a Clausius-Clapeyron expression of the saturation vapour pressure. The vertical profile of specific humidity is retrieved assuming a constant relative humidity for the whole atmospheric column below $500 \mathrm{hPa}$.

\subsection{Sub-grid precipitation and coarse-grid upscaling}

From the climatic variables computed on the artificial surfaces of the vertically extended grid, we can compute the precipitation and temperature at the sub-grid orography.

\subsubsection{From the vertically extended grid to the sub-grid}

For a given native coarse-grid point at a given surface height $\overline{z_{\mathrm{h}}}$, we have a certain number of sub-grid points $k$ of different surface heights $z_{\mathrm{h}}\left(k=1, k_{\max }\right)$. The surface elevation of the native grid comprises of the area-weighted average of all $k$ sub-grid points:

$\overline{z_{\mathrm{h}}}=\frac{\sum_{k=1}^{k_{\max }}\left(z_{\mathrm{h}}(k) s_{\mathrm{a}}(k)\right)}{\sum_{k=1}^{k_{\max }} s_{\mathrm{a}}(k)}$,

where $s_{\mathrm{a}}(k)$ is the area of the sub-grid cell.

In order to compute the heat and moisture budget on a subgrid point $k$, we linearly interpolate a needed surface variable $\phi$ from the bounding vertical levels $l$ and $l+1$. Thus, from the variables computed on the vertically extended grid, we recompute on the sub-grid: the near-surface air temperature $T_{*}$, the surface temperature $T_{\mathrm{S}}$ and integrated saturated specific humidity $q_{\max }$.

Winds are not downscaled in our approach. In the real world, orographic precipitation mostly occurs on wind-faced slopes whilst the other side is generally much drier. On the native grid of ECBilt, winds transport humidity and thus affect precipitation amounts. For our downscaling approach, because winds are not downscaled, in order to mimic the enhancement of precipitation on wind-faced slopes, we sort the sub-grid points by elevation for a given coarse-grid point so that the lowlands before the mountain ranges are treated before the higher altitudes. The lowest grid point is initialized with the coarse-grid value $q_{\mathrm{a}}(k=1)=q_{\mathrm{a}}$. As we compute precipitation for a sorted sub-grid point, we remove available precipitable water from the amount of total precipitable water of the previous grid point. In doing so, we assume that the mountain edges (lowest elevations) are the first affected by moisture influx. However, in our approach two points at the same altitude will have the same amount of precipitation, independently from the wind direction. The model is thus intrinsically unable to reproduce high precipitation on windward slopes and conversely low precipitation on leeward slopes. A foreseen model development will be to sort the sub-grid points depending on wind direction.

\subsubsection{Stratiform precipitation}

Two processes are responsible for stratiform precipitation in ECBilt. First, since the upper atmospheric layer (above $500 \mathrm{hPa}$ ) is assumed to be dry, any vertical moisture export through the $500 \mathrm{hPa}$ level is converted into precipitation. The amount of this export is calculated from the moisture availability at $500 \mathrm{hPa}$, which depends of the local surface topography. For this reason, we expand the computation of moisture export on the vertically extended grid. Following a similar expression as in Haarsma et al. (1997), in case of a negative vertical velocity at $500 \mathrm{hPa}, \omega$, the amount of precipitation is computed as the export of moisture outside the $500 \mathrm{hPa}$ level:

$p_{\text {dyn, ve }}(l=1,11)=-\omega q_{*}(l) / \rho_{\mathrm{w}} g$,

where $q_{*}$ is the precipitable water given by

$q_{*}(l=1,11)=r(l) q_{\mathrm{s}}(p=500 \mathrm{hPa})$, 
with $r$ being the relative humidity. For a given grid point, the relative humidity shows a constant vertical profile. However, its value depends on the local topography since its computation is derived from the vertically integrated saturated specific humidity (Eq. 5):

$r(l=1,11)=q_{\mathrm{a}} / q_{\max }(l)$.

From the stratiform precipitation on the vertically extended grid, $p_{\text {dyn, ve }}(l=1,11)$, we compute the corresponding subgrid precipitation, $p_{\text {dyn,ve }}\left(k=1, k_{\max }\right)$, with a linear interpolation from the bounding vertical levels.

Another contribution to stratiform precipitation is due to moisture excess. In the version of ECBilt included in $i$ LOVECLIM v1.1, stratiform precipitation occurs when the total amount of precipitable water is greater than $\alpha_{q}=90 \%$ of the vertically integrated saturated specific humidity. On the sub-grid points, a similar condition is checked, based on the local total amount of precipitable water, $q_{\mathrm{a}}\left(k=1, k_{\max }\right)$, and the local vertically integrated saturated specific humidity $q_{\max }\left(k=1, k_{\max }\right)$. In the original version of ECBilt, the value for $\alpha_{q}$ was tuned to reproduce the global-scale precipitation pattern. Because of the higher spatial variability in topography, the downscaling induces a change in the precipitation pattern. There is no reason why this tuned $\alpha_{q}$ should be kept unchanged from the original model. In addition, because of the strong non-linearity of the precipitation to elevation, we add the possibility to modify the value of $\alpha_{q}$ depending on the local elevation $z_{\mathrm{h}}\left(l=1, k_{\max }\right)$ :

$\alpha_{q}\left(k=1, k_{\max }\right)=\min \left(\alpha_{q}^{\min }+\left(1-\alpha_{q}^{\min }\right) \frac{z_{\mathrm{h}}(k)}{z_{q}}, 1\right)$,

where $\alpha_{q}^{\min }$ is the value for a point at sea level and $z_{q}$ is the altitude above which the precipitation occurs only if the total precipitable water reaches $100 \%$ saturation. As in Haarsma et al. (1997), stratiform precipitation due to moisture excess is expressed as

$p_{\text {dyn,mc }}\left(k=1, k_{\max }\right)=\frac{q_{\mathrm{a}}-\alpha_{q}(k) q_{\max }(k)}{C_{\mathrm{lh}}(k) \cdot \mathrm{d} t}$,

with $\mathrm{d} t$ being the atmospheric model time step $(4 \mathrm{~h})$ and $C_{\mathrm{lh}}$ is a corrective term to account for latent heat release in the atmosphere associated with the precipitation:

$C_{\mathrm{lh}}\left(k=1, k_{\max }\right)=1 .+\frac{r(k) \rho_{\mathrm{w}} L_{\mathrm{c}} g}{c_{\mathrm{p}} \Delta p_{1}}\left(\frac{\mathrm{d} q_{\max }}{\mathrm{d} T_{650}}\right)(k)$,

with $L_{\mathrm{c}}$ being the latent heat of condensation, $c_{\mathrm{p}}$ the specific heat capacity and $\Delta p_{1}$ the lower layer depth $(500 \mathrm{hPa}) \cdot \frac{\mathrm{d} q_{\max }}{\mathrm{d} T_{350}}$ is obtained from tabulated values of Eq. (5).

For the two contributions of stratiform precipitation, the near-surface air temperature of the sub-grid, $T_{*}\left(k=1, k_{\max }\right)$, is used to determine snow and rain partition with an abrupt transition at $0^{\circ} \mathrm{C}$. Similarly to what is done for coarse-grid precipitation in the standard version of ECBilt (Haarsma et al., 1997; Opsteegh et al., 1998), the sub-grid stratiform precipitations, either snow and rain, are associated with a local release of heat at $350 \mathrm{hPa}$, modifying $T_{350}\left(k=1, k_{\max }\right)$.

\subsubsection{Convective precipitation}

Convective precipitation is assumed to be an adjustment term to reach stability in the atmospheric column. It represents roughly $10 \%$ of the total precipitation in the model. We compute convective precipitation after the stratiform precipitation. If the moisture availability $q_{\mathrm{a}}\left(k=1, k_{\max }\right)$ is still greater than $\alpha_{q}(k) q_{\max }(k)$, then the amount of convective precipitation, $p_{\text {conv }}\left(k=1, k_{\max }\right)$, is computed with the same formulation as in Eq. (12). As for the stratiform precipitation, the convective precipitation is associated with a local heat release affecting the temperature at $350 \mathrm{hPa}, T_{350}\left(k=1, k_{\max }\right)$. After this convective precipitation, we assess stability by comparing the moist adiabatic lapse rate to the local potential temperature at $500 \mathrm{hPa}, \theta\left(k=1, k_{\max }\right)$, computed from the potential temperatures at 350 and $650 \mathrm{hPa}$. The stability is assessed for each individual sub-grid point. If the stability is not reached, we allow a new convective precipitation term computed from $q_{\mathrm{a}}\left(k=1, k_{\max }\right)$. The heat release in the upper atmosphere at each precipitation event tends to increase stability. This is an iterative process and we only go to the next sub-grid point when we reach stability locally.

\subsubsection{Upscaling to the coarse grid}

Following the stratiform and convective iterations on the subgrid, moisture and energy on the native grid have to be updated. On the one hand, the initial coarse-grid moisture is simply reduced by the sum of sub-grid total precipitations, hence readily conserving water. On the other hand, the temperatures at 350 and $650 \mathrm{hPa}$ are recomputed as the mean of the sub-grid temperatures at these levels.

\section{Application and validation}

\subsection{Sub-grid of the Northern Hemisphere}

As an example application, we use a sub-grid domain covering a large part of the Northern Hemisphere (hereafter NH40; Fig. 2). The sub-grid topography comes from ETOPO1 (Amante and Eakins, 2009), projected with a Lambert equalarea projection onto a squared $40 \mathrm{~km} \times 40 \mathrm{~km}$ Cartesian grid. The grid contains $241 \times 241$ points with more than half of the domain being continental areas. This grid was chosen because it corresponds to the ice sheet model grid embedded in $i$ LOVECLIM. The T21 topography depicted in Fig. 2 corresponds to the NH40 topography aggregated to the native model resolution. This is the topography seen by the model when the downscaling is not performed. 


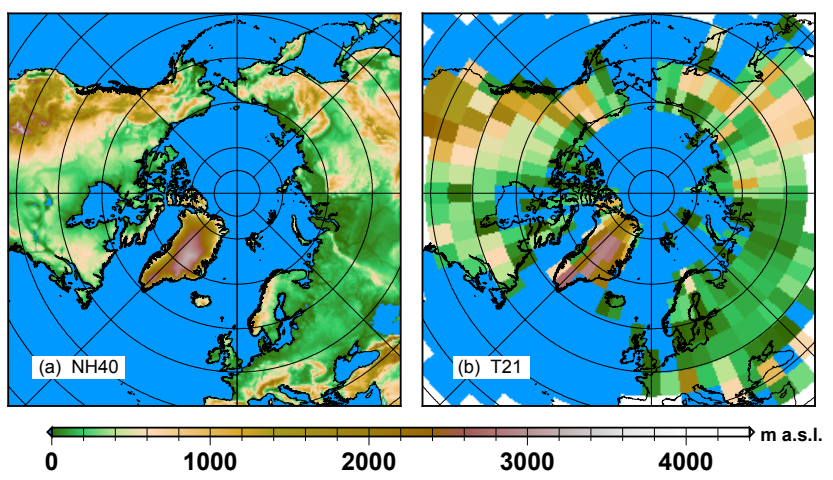

Figure 2. Northern Hemisphere topography from ETOPO1 projected with a Lambert equal area on a Cartesian $40 \mathrm{~km}$ by $40 \mathrm{~km}$ grid (a) and in the native ECBilt grid (b).

\subsubsection{Experimental design}

For model evaluation, we define a control simulation (hereafter CTRL) as 100 years of $i$ LOVECLIM integration under constant pre-industrial external forcing, branched to the standard long-term equilibrated pre-industrial restart. With the same experimental design, we define a series of downscaling experiments (hereafter DOWN) in which we compute the temperature and precipitation on the NH40 grid. For these experiments, we test the importance of three selected parameters: the elevation from which $100 \%$ saturation is needed to initiate precipitation $z_{q}$ in Eq. (11) (2000 and $3500 \mathrm{~m}$ ), the minimum fraction of saturation to initiate precipitation $\alpha_{q}^{\min }$ in Eq. (11) $(0.7,0.75,0.8,0.85,0.9)$ and the lapse rate scaling factor $f_{\mathrm{s}}$ in Eq. (4) $(0.6,0.7,0.8,0.9$ and 1.). We explore the whole matrix of runs, which corresponds to 50 model realizations.

\subsection{Model evaluation}

For model evaluation, we compare the modelled annual mean climatic fields, namely surface temperature and precipitation rate, to an observation-derived dataset. For this, we use a 1970-1999 climatological mean of annual surface temperature of the ERA-Interim reanalysis (Dee et al., 2011) and the long-term mean climatology of annual precipitation of CRU CL-v2 (New et al., 2002). We use ERA-Interim on the $0.125^{\circ} \times 0.125^{\circ}$ resolution for the whole Northern Hemisphere, whilst CRU CL-v2 covers whole continental areas on a $10^{\prime}$ grid. We use bilinear interpolation to generate these data on the NH40 grid. For diagnostic purposes, we also aggregate these data on the T21 grid with the same grid correspondence already used in Roche et al. (2014).

\subsubsection{Surface temperature}

The annual mean surface temperature for ERA-Interim and model outputs on the NH40 and T21 grids is presented in Fig. 3. On the one hand, the general pattern, i.e. the strong
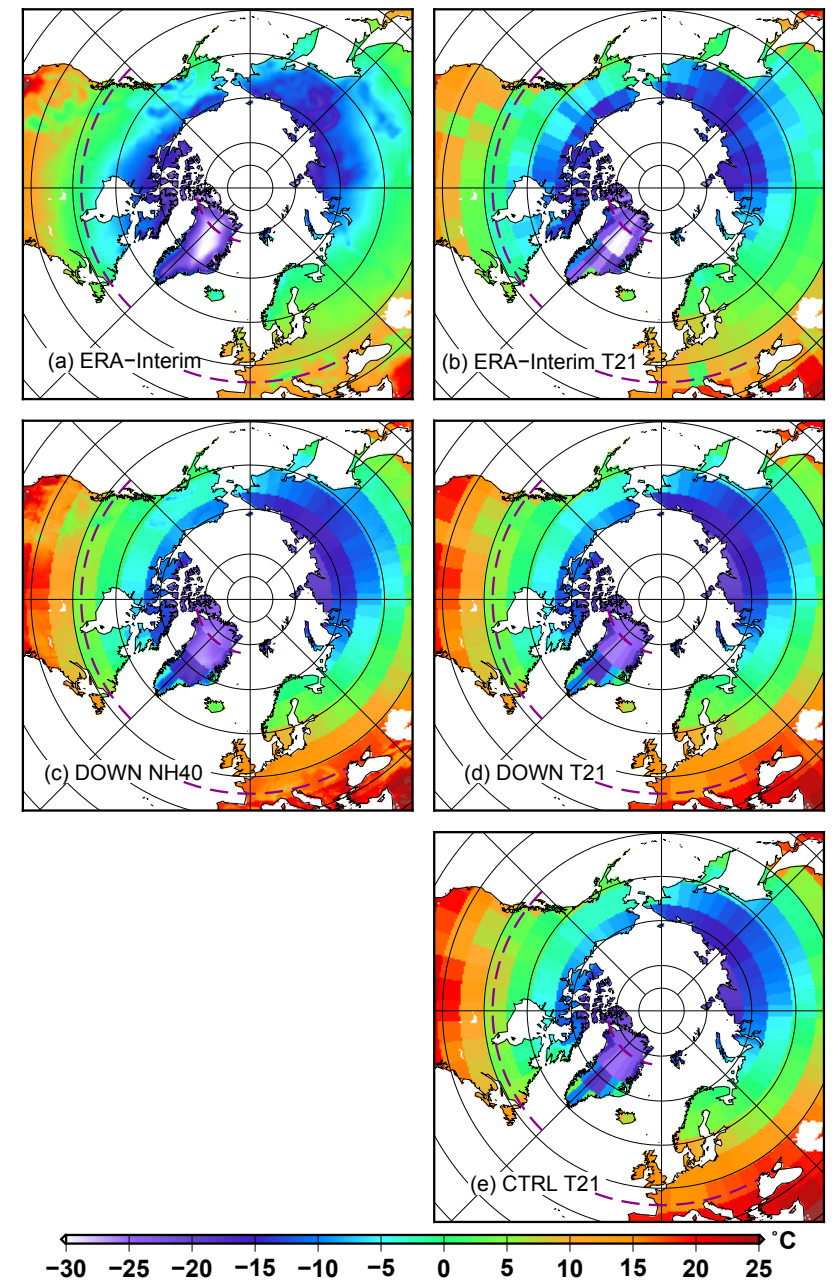

Figure 3. Northern Hemisphere annual mean surface temperature $\left({ }^{\circ} \mathrm{C}\right)$ in: ERA-Interim $(\mathbf{a}, \mathbf{b})$, the $i$ LOVECLIM that includes a downscaling (c, d; with $z_{q}=2000 \mathrm{~m}, \alpha_{q}^{\min }=0.8$ and $\left.f_{\mathrm{s}}=0.6\right)$ and the standard version of $i$ LOVECLIM (e, CTRL). The left panel corresponds to data on the high-resolution grid, whilst on the right data are aggregated to the T21 resolution. The dashed purple lines identify the selected transects used for discussion.

latitudinal cooling, is generally well represented in the CTRL experiment; whilst the model reproduces the cold temperatures in Siberia, elsewhere it is generally too warm, in particular over North America, Greenland and western Europe. The temperature anomaly induced by local topography in the CTRL experiment is also largely underestimated. On the other hand, on the continental scale, our downscaling procedure does not imply important changes in surface temperature relative to the CTRL experiment. This suggests that the downscaling has only a minor impact on atmospheric circulation. However, the downscaling induces important local temperature changes, particularly visible on the $\mathrm{NH} 40$ grid. At this resolution, the temperature is reduced according to the local elevation. In many locations, the native grid is still 
visible on the NH40 model results. The imprint of the native grid remains because the primary effect of the downscaling is to physically compute the distribution of the climatic variables linked to temperature and precipitation according to the sub-grid topography for a given coarse-grid information. By design, this generates discontinuities when moving from two neighbouring cells. Only air advection, which tends to be larger along parallels than meridians, reduces the imprint of the coarse grid.

In Fig. 4, we present the annual mean surface temperature for a selection of downscaling experiments across selected transects: west to east for Europe, North America and Greenland (dashed purple lines in Fig. 3). ERA-Interim temperature shows a strong dependency on elevation. This dependency is remarkably well reproduced for the European transect. However, the warm model bias is only reduced for elevated areas, with only a very limited change at lower elevation. This is because our downscaling methodology strongly relies on topography and is thus not designed to correct broader region model biases that are unrelated to topographic forcing. For the other transects, even if the horizontal temperature gradients are generally better reproduced with the downscaling, the large model bias in the original model induces large errors, only slightly corrected by the downscaling.

To assess general model performance, we present in Fig. 5 a normalized Taylor diagram computed from ERA-Interim and several model outputs. In this figure, we present one selected downscaling experiment (with parameter values: $z_{q}=$ $2000 \mathrm{~m}, \alpha_{q}^{\mathrm{min}}=0.8, f_{\mathrm{s}}=0.6$ ), as the sensitivity of the Taylor diagram to model parameters is very limited. Overall, the model generally shows very good skill in reproducing annual mean surface temperatures, for both the CTRL and DOWN experiments (filled circles). In particular, the model presents a good spatial correlation (greater than 0.9) with a standard deviation only generally slightly overestimated. Because the downscaling does not directly affect the climatic fields at low elevation, we also present in Fig. 5 a normalized Taylor diagram computed from the mountainous grid points only (elevation greater than $800 \mathrm{~m}$, triangles). With this, we can conclude that whilst the downscaling increases the agreement with the ERA-Interim for mountainous grid points, its impact for the whole grid is relatively limited. Interestingly, with and without the downscaling, the performance of the model is better when the lowlands are discarded. As the major model biases are located within these areas (e.g. warm bias of more than $10^{\circ} \mathrm{C}$ around Hudson Bay). Finally, on the native model grid (empty circles), the downscaling does not significantly impact the model performance.

\subsubsection{Precipitation}

The annual mean precipitation rate for both the CRU CL-v2 and the $i$ LOVECLIM model are shown in Fig. 6. The model reproduces some of the major large-scale structures: an east
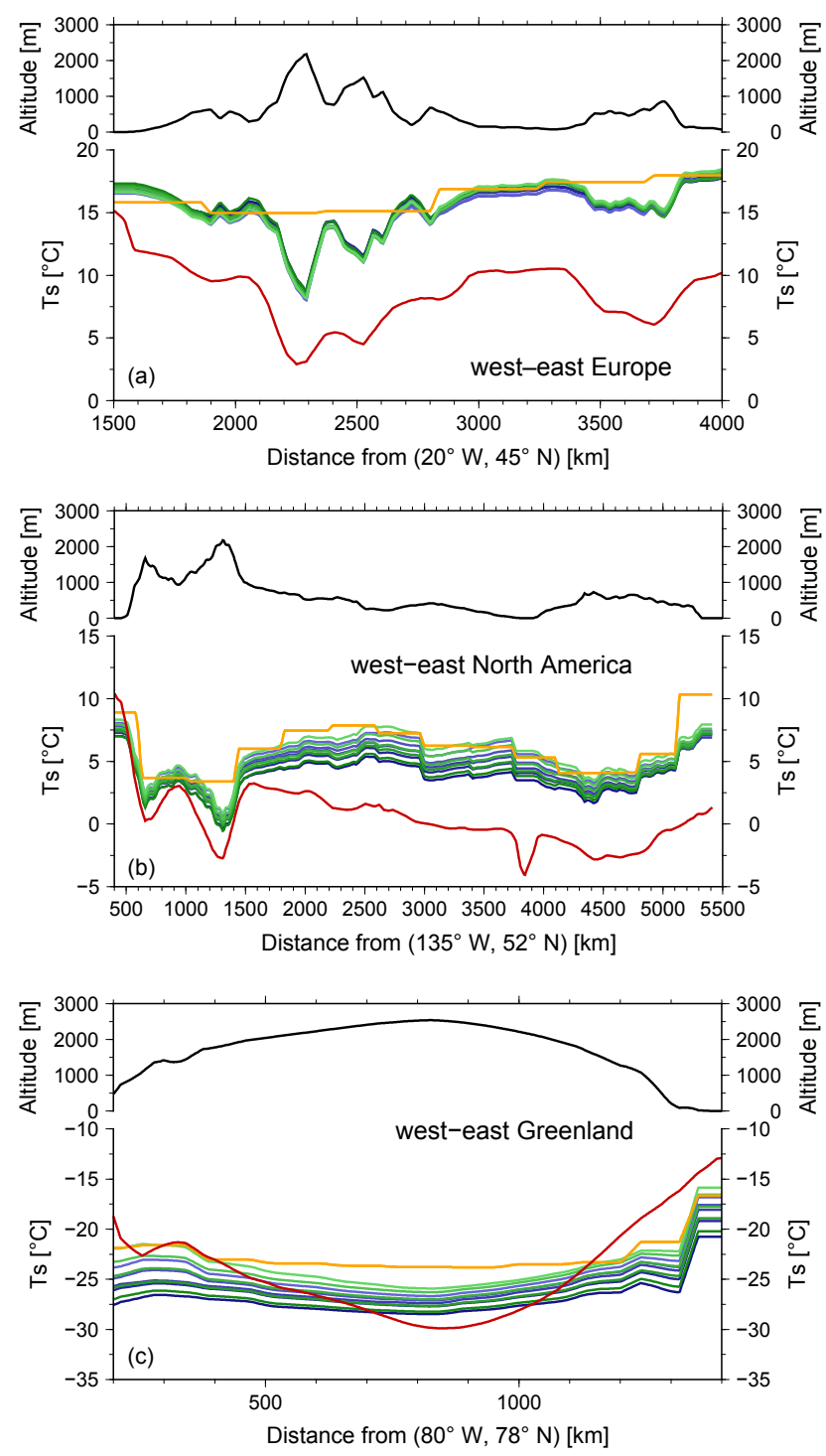

Figure 4. Transects for selected regions: Europe (a), North America (b) and Greenland (c). The upper part of each panel shows the elevation along the transects. The lower part of each panel depicts the annual mean surface temperature along the transects for: ERA-Interim (red), the standard $i$ LOVECLIM (CTRL, orange), the $i$ LOVECLIM including a downscaling with $f_{\mathrm{S}}=1.0$ (blue), the $i$ LOVECLIM including a downscaling with $f_{\mathrm{s}}=0.6$ (green). The different shades of blue and green correspond to $\alpha_{q}^{\mathrm{min}}$ ranging from 0.7 (dark) to 0.9 (light). The downscaling experiments presented in this figure use $z_{q}=2000 \mathrm{~m}$ and a change to $z_{q}=3500 \mathrm{~m}$ has only a very limited effect.

to west decrease in precipitation from the eastern coast of North America, wet Rocky Mountains and a relatively wet western Europe. The model, however, presents important biases in some places. In particular, eastern Siberia, the southern part of the Rocky Mountains and eastern North America are wetter than the CRU CL-v2 dataset. Conversely, the 


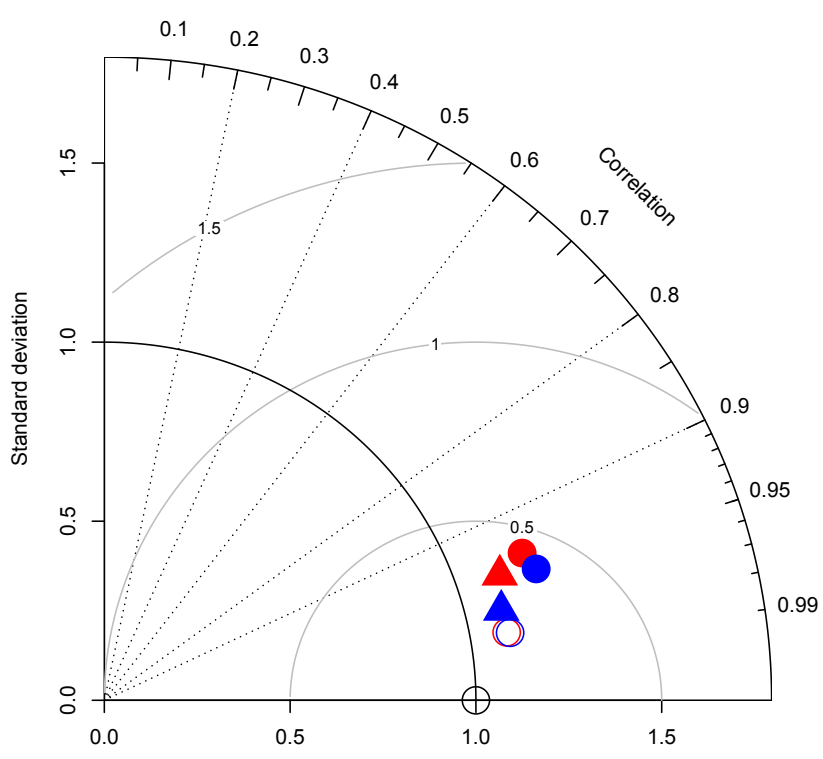

Figure 5. Normalized Taylor diagram on the ERA-Interim annual mean surface temperature for the standard CTRL experiment (red) and a selected downscaling experiment (with $z_{q}=2000 \mathrm{~m}$, $\alpha_{q}^{\min }=0.8$ and $f_{\mathrm{s}}=0.6$ ) (blue). The circles depict the score when all grid points are considered, whilst the triangles stand for points with an elevation greater than $800 \mathrm{~m}$. The filled symbols correspond to the Taylor diagram computed on the high-resolution grid, whilst the empty symbols are for the T21 grid. In this figure, the metrics (standard deviation, correlation and root mean square error) are computed from the annual mean climatic variables. The standard deviation in the observations is used to normalize the standard deviations and the root mean square error.

model is too dry in the eastern Europe and central North American regions. Generally, the CTRL simulation fails at reproducing the precipitation maxima over topographic features. The downscaling produces much more spatial variability, with its main effect being to increase the precipitation over elevated areas. Therefore, we are able to mimic the precipitation pattern in western Europe with precipitation maxima over the Alps, the Scandinavian mountains and the Scottish Highlands (Fig. 7). However, the corresponding precipitation maxima in the observations do not necessarily perfectly coincide with the simulated ones: in the observations, the windward coasts generally experience more precipitation than the interior grid cells. This is particularly visible in the very narrow band (less than $200 \mathrm{~km}$ ) of the extremely high precipitation rate on the western part of North America and along the Norwegian coast in the CRU CL-v2 dataset. Because, we do not take into account the winds in our approach, the main effect of the downscaling is to redistribute the precipitation according to the local topography within a native T21 grid cell. In order to better resolve the fine-scale structures, a redistribution of precipitation according to the wind direction could be a significant improvement in future versions. Over Greenland, the pattern obtained with the down-
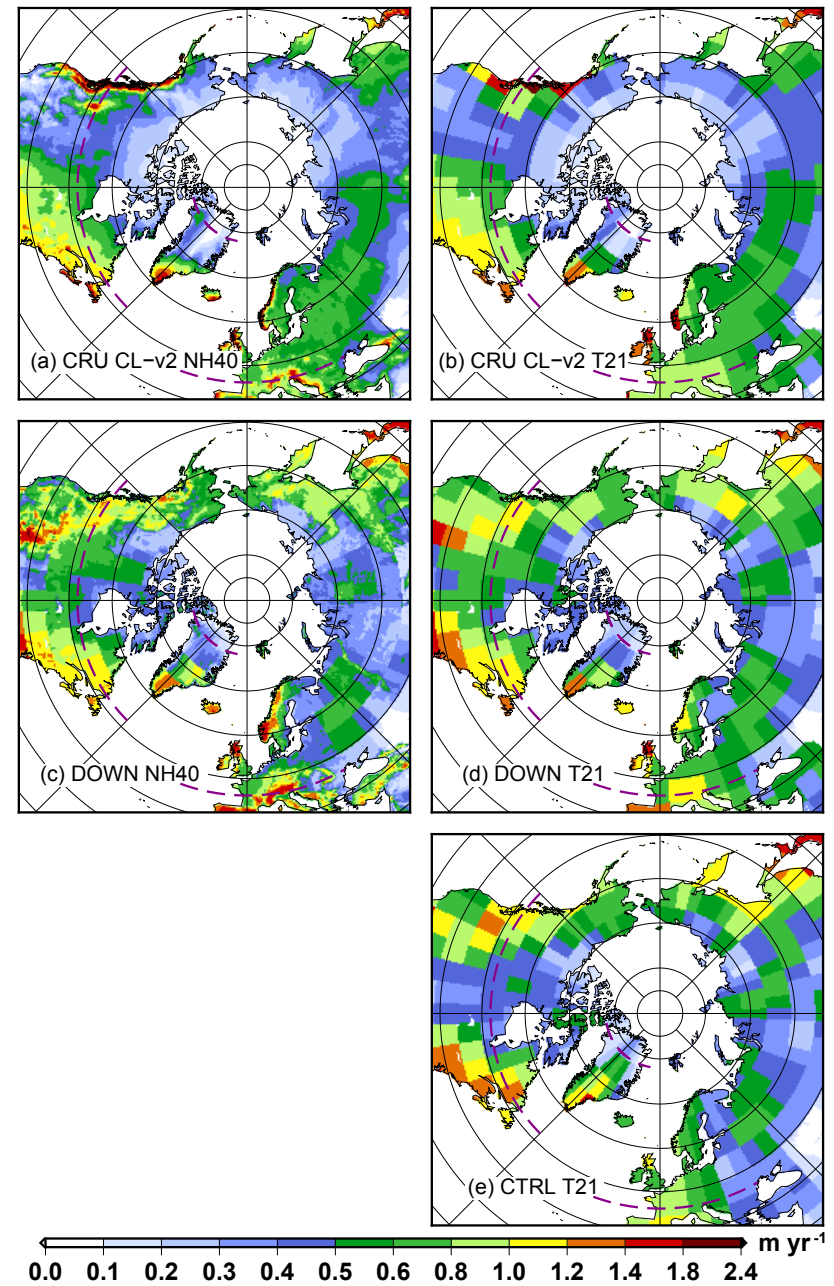

Figure 6. Northern Hemisphere annual mean precipitation rate $\left(\mathrm{m} \mathrm{yr}^{-1}\right)$ in: CRU CL-v2 (a, b), the $i$ LOVECLIM that includes a downscaling (c, d; with $z_{q}=2000 \mathrm{~m}, \alpha_{q}^{\min }=0.8$ and $\left.f_{\mathrm{s}}=0.6\right)$ and the standard version of $i$ LOVECLIM (e, CTRL). The left panels (a, c) corresponds to data on the high-resolution grid, whilst on the right (b, d, e) data are aggregated to the T21 resolution. The dashed purple lines identify the selected transects used for discussion.

scaling is much better than in the standard version with an increased south to north precipitation decrease (Fig. 8). Although the northern part of Greenland is still wetter than the observations, it is drier than in the standard version of the model. Over the Rocky Mountains, the downscaling reproduces some of the local features (Columbia mountain's high precipitation); however, the intrinsic model biases are generally not corrected. Where the model tends to be too wet (eastern Siberia, Alaska and the southern Rocky Mountains), the downscaling experiments are generally also too wet. This is particularly true where the topography is pronounced (southern Rocky Mountains). This means that the model's largescale structures are generally stable and are only slightly impacted by the downscaling. In fact, the first order effect of the 

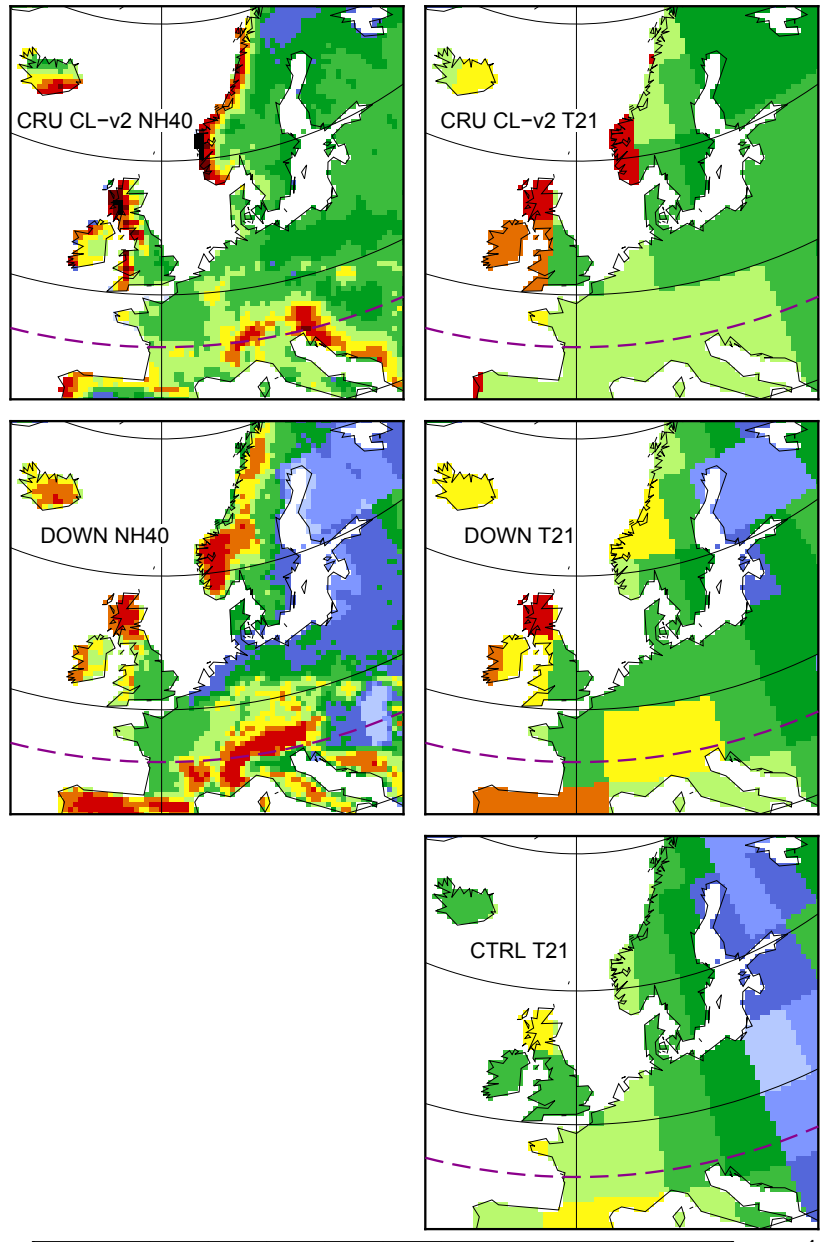

$\begin{array}{lllllllllllll}0.0 & 0.1 & 0.2 & 0.3 & 0.4 & 0.5 & 0.6 & 0.8 & 1.0 & 1.2 & 1.4 & 1.8 & 2.4\end{array}$

Figure 7. Same as Fig. 6 but zoomed over Europe.

downscaling is to redistribute the precipitation according to the topography in a physically consistent way. In fact, there is only a relatively small change in the total amount of precipitation when using the downscaling, as the averaged precipitation in the area between 30 to $90^{\circ} \mathrm{N}$ in the experiments presented in Fig. 6 is only decreased by $2 \%$ in this case.

In Fig. 9, we present the annual mean precipitation rate across selected transects, revealing that for all the selected transects, but in particular for Europe, the CTRL experiment presents too smooth variations in the rate of precipitation. The different downscaling versions simulate much more variability, coinciding with topography variations. In Europe, the fit with observations is relatively good; one likely explanation could be the relatively small bias in the CTRL experiment within this region. However, an east-west divide exists in North America in which downscaling improves the precipitation in the east, but leads to an increase in the wet bias present in CTRL in the west. For Greenland, the CTRL simulations produce a precipitation maxima at the summit of the ice sheet which corresponds to the precipitation minima in
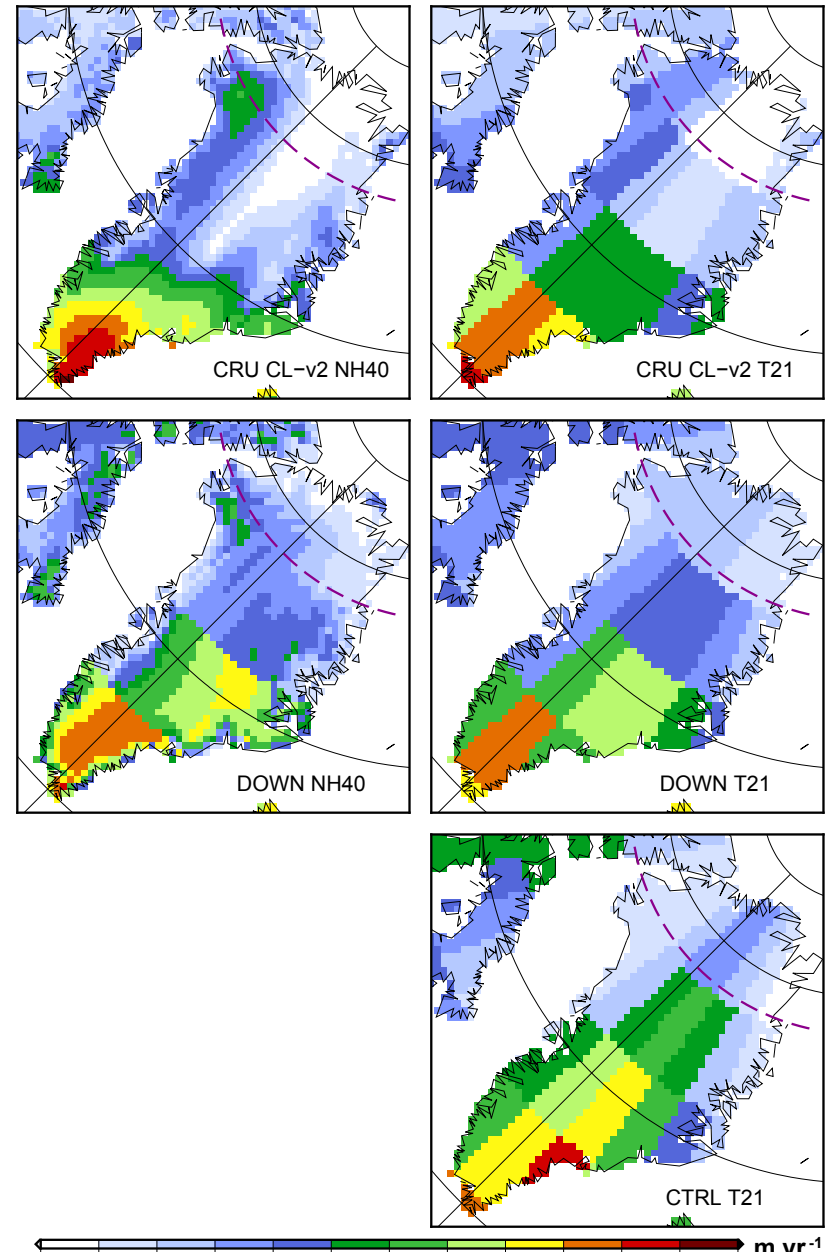

$\begin{array}{lllllllllllll}0.0 & 0.1 & 0.2 & 0.3 & 0.4 & 0.5 & 0.6 & 0.8 & 1.0 & 1.2 & 1.4 & 1.8 & 2.4\end{array}$

Figure 8. Same as Fig. 6 but zoomed over Greenland.

CRU CL-v2 dataset. Conversely, the western flank of the ice sheet for this transect is too dry in the CTRL experiment. Downscaling, however, considerably increases the precipitation along the western margin and produces a meridional precipitation gradient that is in better agreement with the observations. Through specific parameter combinations, it is possible to reduce the wet bias in the central part of the ice sheet; however, the model is still largely too wet over central Greenland, perhaps due to dynamical features not captured by the T21 grid: the coarse resolution facilitates the advection of warm and moist air at the summit of the ice sheet.

A quantitative analysis of model performance is shown on Fig. 10 in which we present normalized Taylor diagrams for the CTRL and a selection of DOWN experiments against CRU CL-v2. On the NH40 grid (filled circles), most of the downscaling experiments improve model performance on one specific metric but not necessarily the others. In particular, a lower value for $\alpha_{q}^{\min }$ tends to reduce the RMSE and to increase the spatial correlation, whilst the standard deviation is reduced. A lower value for $f_{\mathrm{s}}$ also reduces the RMSE and 

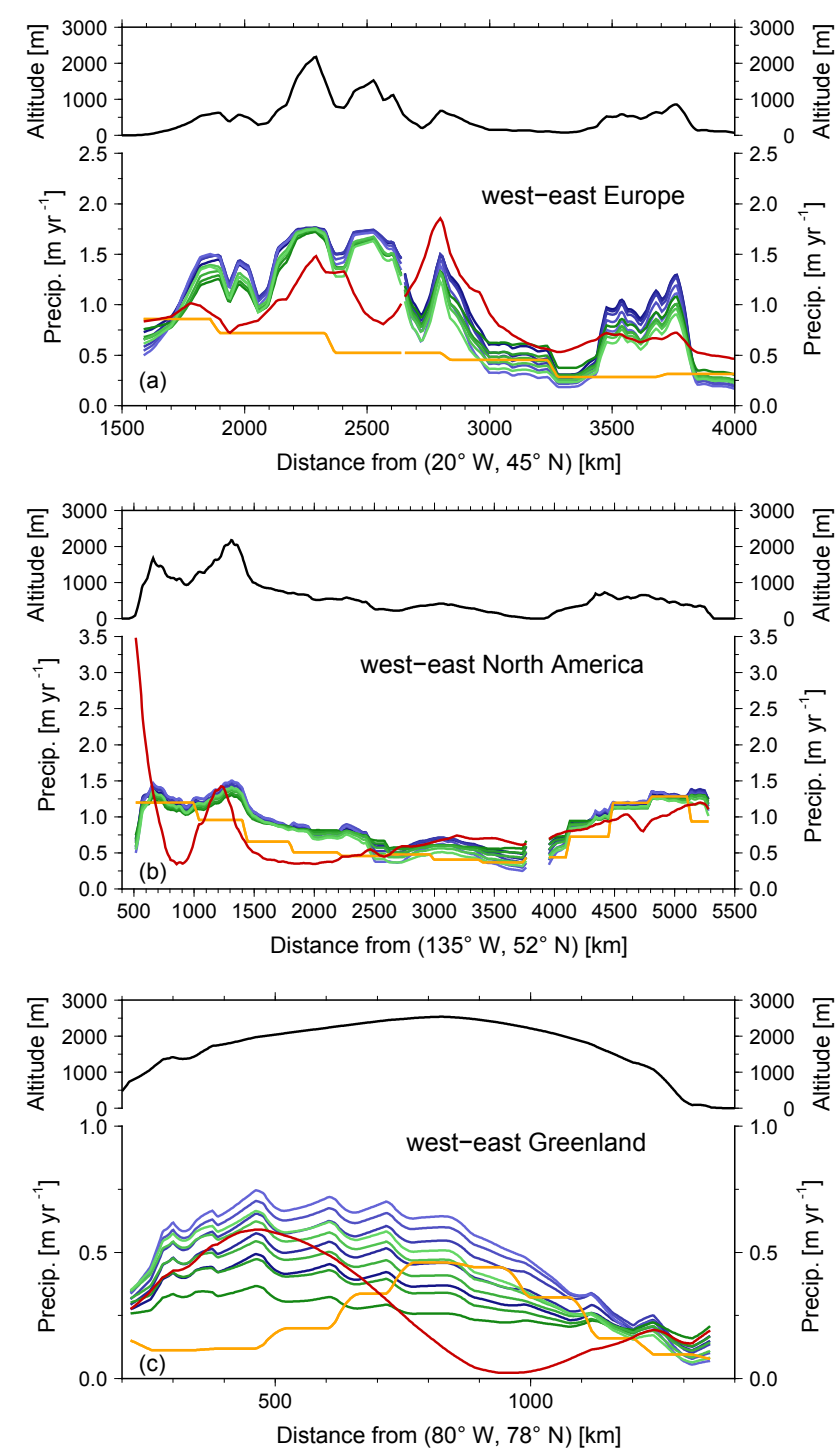

Figure 9. Transects for selected regions: Europe (a), America (b) and Greenland (c). The upper part of each panel shows the elevation along the transects. The lower part of each panel depicts the annual mean precipitation along the transects for: CRU CL-v2 (red), the standard $i$ LOVECLIM (CTRL, orange), the iLOVECLIM including a downscaling with $f_{\mathrm{s}}=1.0$ (blue), the $i$ LOVECLIM including a downscaling with $f_{\mathrm{s}}=0.6$ (green). The different shades of blue and green correspond to $\alpha_{q}^{\mathrm{min}}$ ranging from 0.7 (dark) to 0.9 (light). The downscaling experiments presented in this figure use $z_{q}=2000 \mathrm{~m}$ and a change to $z_{q}=3500 \mathrm{~m}$ has only a very limited effect.

the standard deviation but has almost no impact on the correlation. The parameter $z_{q}$ has a similar effect, but smaller in amplitude, than $f_{\mathrm{s}}$ in the range tested. The real benefit of the downscaling is the better representation of precipitation for mountainous grid cells (elevations greater than $800 \mathrm{~m}$, filled triangles). In this case, all the downscaling experiments present a better agreement with CRU CL-v2. The spatial cor- relation is in particular greatly improved (from about 0.25 to more than 0.4). At the original model resolution (empty symbols), some selected downscaling experiments present an overall improvement. Generally, the downscaling has a nonnegligible impact on the precipitation fields on the T21 grid. For multi-millennial integrations, these changes in the hydrological cycle can have important feedbacks on the simulated climate. Although it is potentially prudent that a new tuning of the model parameters be performed, in order to avoid this, and for further applications, the parameter combination $z_{q}=2000 \mathrm{~m}, \alpha_{q}^{\min }=0.8$ and $f_{\mathrm{s}}=0.6$ is preferred because it produces an overall improvement of all metrics on the NH40 grid, as it only has a minor change from the CTRL experiment on the T21 grid.

Figure 11 presents quantitative metrics (spatial correlation, standard deviation and root mean square error) as a function of parameter values. The parameters that have the strongest influence on the simulated precipitation are $f_{\mathrm{s}}$ and $\alpha_{q}^{\mathrm{min}}$. A lower value for these parameters tends to produce a higher spatial correlation, lower standard deviation and a lower root mean square error. However, for $z_{q}=2000 \mathrm{~m}$, low values for the two other parameters can lead to an underestimation of the standard deviation. The standard deviation and the root mean square error have a similar response to a change in parameters, the spatial correlation is mostly sensitive to the $\alpha_{q}^{\min }$ parameter, with a higher correlation for lower values of this parameter.

\section{Summary and perspectives}

We have presented the inclusion of a dynamical downscaling of temperature and precipitation on a $40 \mathrm{~km}$ by $40 \mathrm{~km}$ grid of the Northern Hemisphere into a T21 resolution atmospheric model of intermediate complexity. The methodology chosen for the downscaling procedure replicates the relevant parts of the model physics needed for temperature and precipitation on the high-resolution grid. An upscaling is performed from the high-resolution precipitation and temperature data, which takes into account the climatic feedback of sub-grid precipitation on the native grid climate. The scheme is conservative and, as such, is suitable for long-term integration.

We tested various parameters related to the temperature and precipitation at high resolution. The temperature is only locally impacted by the downscaling with a cooling over mountainous areas. For precipitation, we have shown that we are able to generate a field at high resolution, which presents a better agreement with observations compared to the native coarse-resolution atmosphere for mountainous regions. The downscaling drastically increases spatial variability compared to the standard version of the model. Downscaling is, however, unable to correct for large-scale model biases, including biases in atmospheric circulation and model simplification, such that model performance is best when the biases in the standard version are low. In particular, currently 

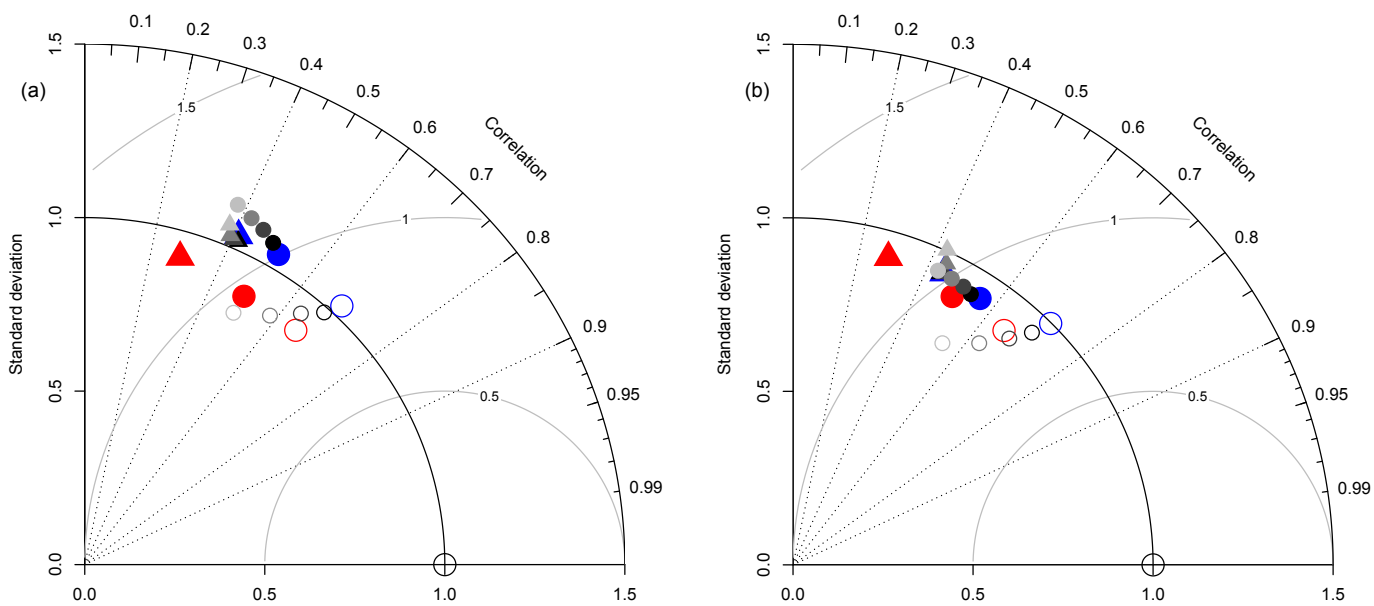

Figure 10. Normalized Taylor diagrams on the CRU CL-v2 annual mean precipitation rate for the standard CTRL experiment (red) and a series of DOWN experiments (grey and blue). The circles depict the score when all grid points are considered, whilst the triangles stand for points with an elevation greater than $800 \mathrm{~m}$. The filled symbols correspond to the Taylor Diagram computed on the high-resolution grid whilst the empty symbols are for the T21 grid. All the DOWN experiments presented here use $z_{q}=2000 \mathrm{~m}$. The different shades of greys are for different $\alpha_{q}^{\text {min }}$ ranging from 0.75 (dark) to 0.9 (light), for $f_{\mathrm{s}}=1.0$ (a) and $f_{\mathrm{s}}=0.6$ (b). DOWN with $z_{q}=2000 \mathrm{~m}, \alpha_{q}^{\mathrm{min}}=0.7$ and $f_{\mathrm{s}}=1.0$ (a) and DOWN with $z_{q}=2000 \mathrm{~m}, \alpha_{q}^{\mathrm{min}}=0.7$ and $f_{\mathrm{s}}=0.6$ (b) are in blue. In this figure, the metrics (standard deviation, correlation and root mean square error) are computed from the annual mean climatic variables. The standard deviation in the observations is used to normalize the standard deviations and the root mean square error.
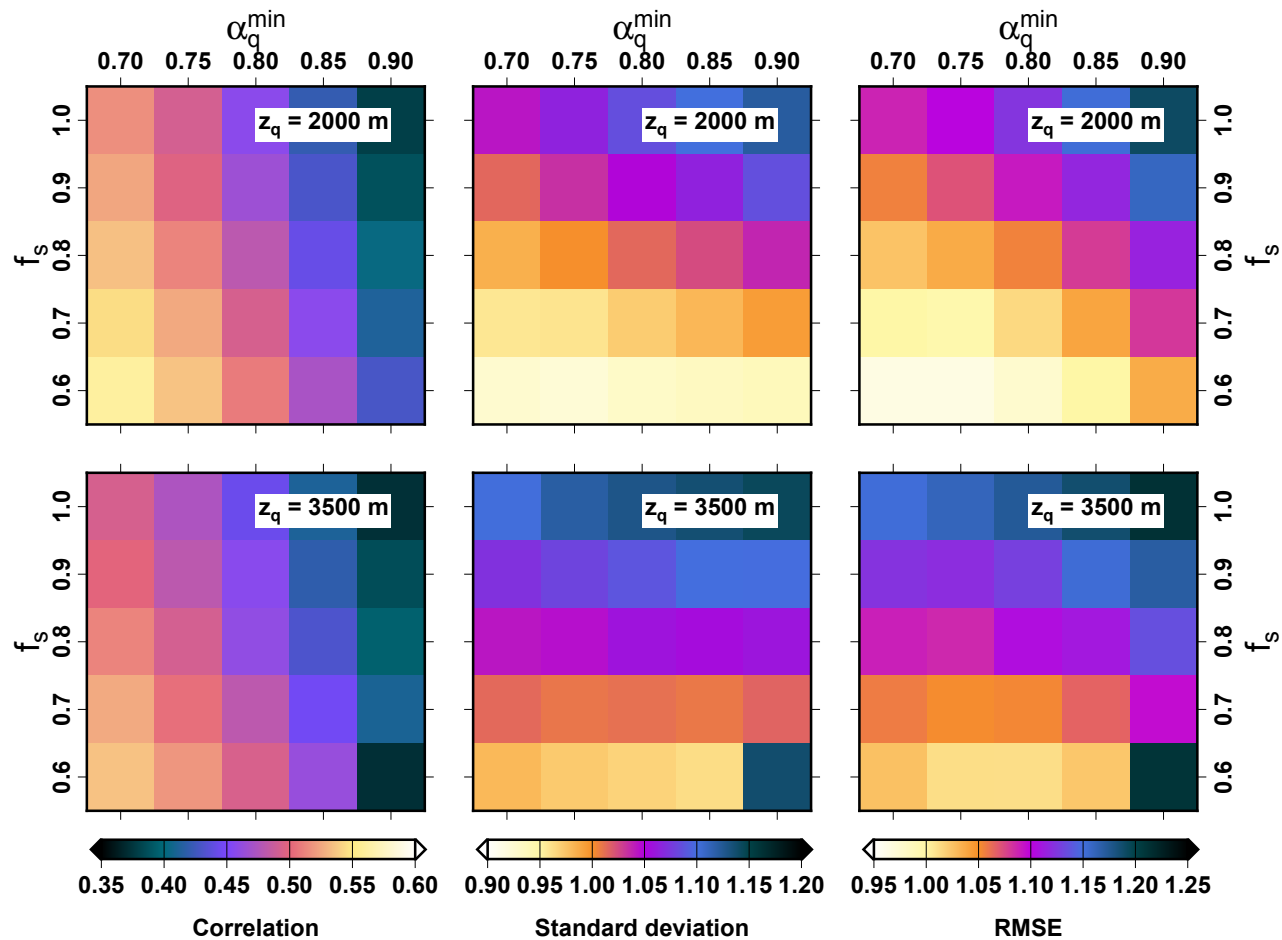

Figure 11. Correlation, normalized standard deviation and normalized root mean square error computed from annual mean precipitation as a function of the parameter values for the downscaling experiments. The normalization is done by dividing the modelled metric (either standard deviation or root mean square error) by the standard deviation in the observations. 
the model presents only one moist layer and has no explicit representation of clouds. Further development could include an iterative scheme for clouds and that these clouds could relate to precipitation. Such a development could be tested on the high-resolution grid with a specific calibration of convective clouds based on topography. Another model limitation is the lack of a diurnal cycle. This can be a reason for the relatively large precipitation data and model mismatch for coastal areas where sea breeze can initiate convection.

A note of caution, our downscaling mostly relies on the internal physics of the original ECBilt model. Given the relative simplicity of the scheme, the small-scale processes are not explicitly taken into account. As such, the methodology presented here might not always be suitable for highresolution modelling where the small-scale processes can become dominant. Also in our approach, winds are not used for the precipitation distribution within a coarse grid. A foreseen future model development would be to implement a scheme to increase the precipitation for windward points relative to the leeward ones.

We have shown that the downscaling has only a limited impact on the temperature field at the T21 resolution. This is partly due to the fact that the large-scale atmospheric circulation remains mostly unchanged whilst using the downscaling (not shown). However, at T21 resolution, there are some local changes in precipitation, though these are localized predominately over mountainous areas. Thus, some components of the model, such as continental runoff and ultimately ocean or also vegetation, are impacted by the inclusion of the downscaling. In one simulation of 1000 years that we integrated for one particular parameter combination, we obtained a modified state for the ocean and the vegetation. Although the total amount of precipitation in the Northern Hemisphere is not modified substantially, the spatial distribution of precipitation in the different runoff basins led to a reduction of the Atlantic meridional overturning circulation strength and to a shallower branch of the upper branch of the thermohaline circulation in that particular simulation. To avoid this global climate drift from the CTRL experiment, we present only 100 years of model integration ensuring a limited role of the downscaling feedbacks on the global climate. However, for longer integration, the model might need some adjustment in order to correctly reproduce the presentday state of the climate system.

In an earlier version of the model that included a coupled ice sheet, Roche et al. (2014) demonstrated the poor performance of the surface mass balance when it is computed from bilinearly interpolated precipitation in simulating the present-day topography of the Greenland Ice Sheet. From the downscaled atmospheric fields shown here, it is now possible to compute the surface mass balance required by the ice sheet model embedded in $i$ LOVECLIM. This downscaled surface mass balance will explicitly take into account the sub-grid temperature and precipitation according to the local orography. With this, we aim at better reproducing the non-linear nature of the surface mass balance and in particular the position of the ablation zone at the margin. Foreseen applications include interactively coupled ice-sheet-climate models thanks to the downscaled atmospheric fields; although the artificial discontinuities due to the imprint of the coarse native grid cell in the downscaled field are still an important drawback of the method presented. Ice sheet mass balance is not the only possible application as our methodology is not grid specific and can be used to compute high-resolution temperature and precipitation required for any submodel. Thus, foreseen applications include the computation of high-resolution terrestrial water cycles, in particular for permafrost and vegetation dynamics.

Code availability. The iLOVECLIM source code is based on the LOVECLIM model version 1.2 whose code is accessible at http:// www.elic.ucl.ac.be/modx/elic/index.php?id=289 (UCL, 2018). The developments on the $i$ LOVECLIM source code are hosted at http: //forge.ipsl.jussieu.fr/ludus (IPSL, 2018), but are not publicly available due to copyright restrictions. Access can be granted on demand by request to $\mathrm{D}$. M. Roche (didier.roche@1sce.ipsl.fr) to those who conduct research in collaboration with the $i$ LOVECLIM user group. For this work we used the model at revision 706.

Author contributions. AQ and DR designed the project. DP and CD contributed to the discussions on practical implementation. AQ and DR implemented the new functionality in the climate model. AQ performed the simulations. All authors participated in the analysis of model outputs and the manuscript writing.

Competing interests. The authors declare that they have no conflict of interest.

Acknowledgements. This is a contribution to ERC project ACCLIMATE; the research leading to these results has received funding from the European Research Council under the European Union's Seventh Framework Programme (FP7/2007-2013)/ERC grant agreement 339108. Didier M. Roche acknowledges financial support from the CNRS. Christophe Dumas and Didier Paillard acknowledge financial support from the CEA. The authors gratefully thank Mathieu Vrac and Kenji Izumi for fruitful discussions, and Brett Metcalfe for proof-reading. We thank Jeremy Fyke as well as one anonymous reviewer for their insightful comments. We acknowledge the Institut Pierre Simon Laplace for hosting the $i$ LOVECLIM model code under the LUDUS framework project (https://forge.ipsl.jussieu.fr/ludus).

Edited by: Gerd A. Folberth

Reviewed by: Jeremy Fyke and one anonymous referee 


\section{References}

Amante, C. and Eakins, B.: ETOPO1 1 Arc-Minute Global Relief Model: Procedures, Data Sources and Analysis, NOAA Technical Memorandum NESDIS NGDC-24, National Geophysical Data Center, NOAA, 2009.

Archer, D. and Brovkin, V.: The millennial atmospheric lifetime of anthropogenic $\mathrm{CO}_{2}$, Climatic Change, 90, 283-297, https://doi.org/10.1007/s10584-008-9413-1, 2008.

Berger, A., Loutre, M. F., and Gallée, H.: Sensitivity of the LLN climate model to the astronomical and $\mathrm{CO}_{2}$ forcings over the last $200 \mathrm{ky}$, Clim. Dynam., 14, 615-629, https://doi.org/10.1007/s003820050245, 1998.

Bouttes, N., Paillard, D., Roche, D. M., Brovkin, V., and Bopp, L.: Last Glacial Maximum $\mathrm{CO}_{2}$ and $\delta^{13} \mathrm{C}$ successfully reconciled, Geophys. Res. Lett., 38, L02705, https://doi.org/10.1029/2010GL044499, 2011.

Bouttes, N., Roche, D. M., Mariotti, V., and Bopp, L.: Including an ocean carbon cycle model into iLOVECLIM (v1.0), Geosci. Model Dev., 8, 1563-1576, https://doi.org/10.5194/gmd-8-15632015, 2015.

Brovkin, V., Ganopolski, A., Archer, D., and Rahmstorf, S.: Lowering of glacial atmospheric $\mathrm{CO}_{2}$ in response to changes in oceanic circulation and marine biogeochemistry, Paleoceanography, 22, https://doi.org/10.1029/2006PA001380, 2007.

Bügelmayer, M., Roche, D. M., and Renssen, H.: Representing icebergs in the $i$ LOVECLIM model (version 1.0) - a sensitivity study, Geosci. Model Dev., 8, 2139-2151, https://doi.org/10.5194/gmd-8-2139-2015, 2015.

Calov, R., Ganopolski, A., Petoukhov, V., Claussen, M., and Greve, R.: Large-scale instabilities of the Laurentide ice sheet simulated in a fully coupled climate-system model, Geophys. Res. Lett., 29, 2216, https://doi.org/10.1029/2002GL016078, 2002.

Calov, R., Ganopolski, A., Petoukhov, V., Claussen, M., Brovkin, V., and Kubatzki, C.: Transient simulation of the last glacial inception. Part II: sensitivity and feedback analysis, Clim. Dynam., 24, 563-576, https://doi.org/10.1007/s00382-005-0008-5, 2005.

Charbit, S., Kageyama, M., Roche, D., Ritz, C., and Ramstein, G.: Investigating the mechanisms leading to the deglaciation of past continental northern hemisphere ice sheets with the CLIMBER GREMLINS coupled model, Global Planet. Change, 48, 253273, 2005.

Claussen, M., Mysak, L. A., Weaver, A. J., Crucifix, M., Fichefet, T., Loutre, M.-F., Weber, S. L., Alcamo, J., Alexeev, V. A., Berger, A., Calov, R., Ganopolski, A., Goosse, H., Lohmann, G., Lunkeit, F., Mokhov, I. I., Petoukhov, V., Stone, P., and Wang, Z.: Earth system models of intermediate complexity: closing the gap in the spectrum of climate system models, Clim. Dynam., 18, 579-586, 2002.

Dee, D. P., Uppala, S. M., Simmons, A. J., Berrisford, P., Poli, P., Kobayashi, S., Andrae, U., Balmaseda, M. A., Balsamo, G., Bauer, P., Bechtold, P., Beljaars, A. C. M., van de Berg, L., Bidlot, J., Bormann, N., Delsol, C., Dragani, R., Fuentes, M., Geer, A. J., Haimberger, L., Healy, S. B., Hersbach, H., Hólm, E. V., Isaksen, L., Kållberg, P., Köhler, M., Matricardi, M., McNally, A. P., Monge-Sanz, B. M., Morcrette, J.-J., Park, B.-K., Peubey, C., de Rosnay, P., Tavolato, C., Thépaut, J.-N., and Vitart, F.: The ERA-Interim reanalysis: configuration and performance of the data assimilation system, Q. J. Roy. Meteorol. Soc., 137, 553597, https://doi.org/10.1002/qj.828, 2011.
Edwards, N. R. and Marsh, R.: Uncertainties due to transportparameter sensitivity in an efficient 3-D ocean-climate model, Clim. Dynam., 24, 415-433, https://doi.org/10.1007/s00382004-0508-8, 2005.

Ettema, J., Broeke, M. R. v. d., Meijgaard, E. v., Berg, W. J. v. d., Bamber, J. L., Box, J. E., and Bales, R. C.: Higher surface mass balance of the Greenland ice sheet revealed by high-resolution climate modeling, Geophys. Res. Lett., 36, https://doi.org/10.1029/2009GL038110, 2009.

Fyke, J. G., Weaver, A. J., Pollard, D., Eby, M., Carter, L., and Mackintosh, A.: A new coupled ice sheet/climate model: description and sensitivity to model physics under Eemian, Last Glacial Maximum, late Holocene and modern climate conditions, Geosci. Model Dev., 4, 117-136, https://doi.org/10.5194/gmd-4117-2011, 2011.

Gallée, H., Van Yperselb, J. P., Fichefet, T., Marsiat, I., Tricot, C., and Berger, A.: Simulation of the last glacial cycle by a coupled, sectorially averaged climate-ice sheet model: 2 . Response to insolation and $\mathrm{CO}_{2}$ variations, J. Geophys. Res.-Atmos., 97, 15713-15740, https://doi.org/10.1029/92JD01256, 1992.

Ganopolski, A., Rahmstorf, S., Petoukhov, V., and Claussen, M.: Simulation of modern and glacial climates with a coupled global model of intermediate complexity, Nature, 391, 351-356, https://doi.org/10.1038/34839, 1998.

Gardner, A. S., Sharp, M. J., Koerner, R. M., Labine, C., Boon, S., Marshall, S. J., Burgess, D. O., and Lewis, D.: Near-Surface Temperature Lapse Rates over Arctic Glaciers and Their Implications for Temperature Downscaling, J. Climate, 22, 4281-4298, https://doi.org/10.1175/2009JCLI2845.1, 2009.

Goelzer, H., Huybrechts, P., Loutre, M.-F., and Fichefet, T.: Last Interglacial climate and sea-level evolution from a coupled ice sheet-climate model, Clim. Past, 12, 2195-2213, https://doi.org/10.5194/cp-12-2195-2016, 2016.

Goosse, H., Brovkin, V., Fichefet, T., Haarsma, R., Huybrechts, P., Jongma, J., Mouchet, A., Selten, F., Barriat, P.-Y., Campin, J.M., Deleersnijder, E., Driesschaert, E., Goelzer, H., Janssens, I., Loutre, M.-F., Morales Maqueda, M. A., Opsteegh, T., Mathieu, P.-P., Munhoven, G., Pettersson, E. J., Renssen, H., Roche, D. M., Schaeffer, M., Tartinville, B., Timmermann, A., and Weber, S. L.: Description of the Earth system model of intermediate complexity LOVECLIM version 1.2, Geosci. Model Dev., 3, 603-633, https://doi.org/10.5194/gmd-3-603-2010, 2010.

Gregory, J. M., Browne, O. J. H., Payne, A. J., Ridley, J. K., and Rutt, I. C.: Modelling large-scale ice-sheet-climate interactions following glacial inception, Clim. Past, 8, 1565-1580, https://doi.org/10.5194/cp-8-1565-2012, 2012.

Haarsma, R. J., Selten, F. M., Opsteegh, J. D., Lenterink, G., and Liu, Q.: ECBILT: A coupled atmosphere ocean sea-ice model for climate predictability studies, KNMI technical report TR-195, De Bilt, The Netherlands, available at: http://bibliotheek.knmi. nl/knmipubTR/TR195.pdf (last access: January 2018), 1997.

Huybrechts, P., Janssens, I., Poncin, C., and Fichefet, T.: The response of the Greenland ice sheet to climate changes in the $21 \mathrm{st}$ century by interactive coupling of an AOGCM with a thermomechanical ice-sheet model, Ann. Glaciol., 35, 409-415, 2002.

IPSL (Institut Pierre Simon Laplace): Server dedicated to the IPSL models code management, available at: http://forge.ipsl.jussieu. fr/ludus, last access: January 2018. 
Kitover, D. C., van Balen, R., Roche, D. M., Vandenberghe, J., and Renssen, H.: Advancement toward coupling of the VAMPER permafrost model within the Earth system model iLOVECLIM (version 1.0): description and validation, Geosci. Model Dev., 8, 1445-1460, https://doi.org/10.5194/gmd-8-1445-2015, 2015.

Levavasseur, G., Vrac, M., Roche, D. M., Paillard, D., Martin, A., and Vandenberghe, J.: Present and LGM permafrost from climate simulations: contribution of statistical downscaling, Clim. Past, 7, 1225-1246, https://doi.org/10.5194/cp-7-1225-2011, 2011.

Loutre, M. F., Mouchet, A., Fichefet, T., Goosse, H., Goelzer, H., and Huybrechts, P.: Evaluating climate model performance with various parameter sets using observations over the recent past, Clim. Past, 7, 511-526, https://doi.org/10.5194/cp-7-511-2011, 2011.

Luthi, D., Le Floch, M., Bereiter, B., Blunier, T., Barnola, J.-M., Siegenthaler, U., Raynaud, D., Jouzel, J., Fischer, H., Kawamura, K., and Stocker, T. F.: High-resolution carbon dioxide concentration record 650,000-800,000 years before present, Nature, 453, 379-382, https://doi.org/10.1038/nature06949, 2008.

Marshall, S. J., Sharp, M. J., Burgess, D. O., and Anslow, F. S.: Near-surface-temperature lapse rates on the Prince of Wales Icefield, Ellesmere Island, Canada: implications for regional downscaling of temperature, Int. J. Climatol., 27, 385-398, https://doi.org/10.1002/joc.1396, 2007.

Minder, J. R., Mote, P. W., and Lundquist, J. D.: Surface temperature lapse rates over complex terrain: Lessons from the Cascade Mountains, J. Geophys. Res.-Atmos., 115, D14122, https://doi.org/10.1029/2009JD013493, 2010.

New, M., Lister, D., Hulme, M., and Makin, I.: A high-resolution data set of surface climate over global land areas, Climate Res., 21, 1-25, https://doi.org/10.3354/cr021001, 2002.

Opsteegh, J. D., Haarsma, R. J., Selten, F. M., and Kattenberg, A.: ECBILT: a dynamic alternative to mixed boundary conditions in ocean models, Tellus A, 50, 348-367, https://doi.org/10.1034/j.1600-0870.1998.t01-1-00007.x, 1998.

Petoukhov, V., Ganopolski, A., Brovkin, V., Claussen, M., Eliseev, A., Kubatzki, C., and Rahmstorf, S.: CLIMBER-2: a climate system model of intermediate complexity. Part I: model description and performance for present climate, Clim. Dynam., 16, 1-17, 2000.

Ridgwell, A. and Hargreaves, J. C.: Regulation of atmospheric $\mathrm{CO}_{2}$ by deep-sea sediments in an Earth system model, Global Biogeochem. Cy., 21, GB2008, https://doi.org/10.1029/2006GB002764, 2007.

Robinson, A., Calov, R., and Ganopolski, A.: An efficient regional energy-moisture balance model for simulation of the Greenland Ice Sheet response to climate change, The Cryosphere, 4, 129144, https://doi.org/10.5194/tc-4-129-2010, 2010.

Roche, D. M.: $\delta^{18} \mathrm{O}$ water isotope in the $i$ LOVECLIM model (version 1.0) - Part 1: Implementation and verification, Geosci. Model Dev., 6, 1481-1491, https://doi.org/10.5194/gmd-6-14812013, 2013.
Roche, D. M. and Caley, T.: $\delta^{18} \mathrm{O}$ water isotope in the $i$ LOVECLIM model (version 1.0) - Part 2: Evaluation of model results against observed $\delta^{18} \mathrm{O}$ in water samples, Geosci. Model Dev., 6, 14931504, https://doi.org/10.5194/gmd-6-1493-2013, 2013.

Roche, D. M., Dumas, C., Bügelmayer, M., Charbit, S., and Ritz, C.: Adding a dynamical cryosphere to $i$ LOVECLIM (version 1.0): coupling with the GRISLI ice-sheet model, Geosci. Model Dev., 7, 1377-1394, https://doi.org/10.5194/gmd-7-1377-2014, 2014.

UCL (Univerité catholique de Louvain): LOVECLIM model source code, available at: http://www.elic.ucl.ac.be/modx/index.php? id=289, last access: January 2018.

Vetter, T., Huang, S., Aich, V., Yang, T., Wang, X., Krysanova, V., and Hattermann, F.: Multi-model climate impact assessment and intercomparison for three large-scale river basins on three continents, Earth Syst. Dynam., 6, 17-43, https://doi.org/10.5194/esd6-17-2015, 2015.

Vizcaíno, M., Mikolajewicz, U., Gröger, M., Maier-Reimer, E., Schurgers, G., and Winguth, A. M. E.: Long-term ice sheetclimate interactions under anthropogenic greenhouse forcing simulated with a complex Earth System Model, Clim. Dynam., 31, 665-690, https://doi.org/10.1007/s00382-008-0369-7, 2008.

Vizcaíno, M., Mikolajewicz, U., Jungclaus, J., and Schurgers, G.: Climate modification by future ice sheet changes and consequences for ice sheet mass balance, Clim. Dynam., 34, 301-324, https://doi.org/10.1007/s00382-009-0591-y, 2010.

Vrac, M., Marbaix, P., Paillard, D., and Naveau, P.: Nonlinear statistical downscaling of present and LGM precipitation and temperatures over Europe, Clim. Past, 3, 669-682, https://doi.org/10.5194/cp-3-669-2007, 2007.

Weaver, A. J., Eby, M., Fanning, A. F., and Wiebe, E. C.: Simulated influence of carbon dioxide, orbital forcing and ice sheets on the climate of the Last Glacial Maximum, Nature, 394, 847853, https://doi.org/10.1038/29695, 1998.

Weaver, A. J., Eby, M., Wiebe, E. C., Bitz, C. M., Duffy, P. B., Ewen, T. L., Fanning, A. F., Holland, M. M., MacFadyen, A., Matthews, H. D., Meissner, K. J., Saenko, O., Schmittner, A., Wang, H., and Yoshimori, M.: The UVic earth system climate model: Model description, climatology, and applications to past, present and future climates, Atmos.-Ocean, 39, 361-428, https://doi.org/10.1080/07055900.2001.9649686, 2001.

Wolff, E. W.: Greenhouse gases in the Earth system: a palaeoclimate perspective, Philosophical Transactions of the Royal Society of London A: Mathematical, Phys. Eng. Sci., 369, 2133 2147, https://doi.org/10.1098/rsta.2010.0225, 2011. 